\title{
The Anti-stress Effects of Guangdong Herbal Tea on Immunocompromise in Mice Loaded with Restraint Stress
}

\author{
Rong-Rong He, Bun Tsoi, Yi-Fang Li, Xin-Sheng Yao, and Hiroshi Kurihara* \\ Institute of Traditional Chinese Medicine \& Natural Products, Jinan University, 601 Huangpu Avenue West, Guangzhou 510632, China
}

(Received December 24, 2010; Accepted March 3, 2011)

\begin{abstract}
Guangdong Herbal Tea (GHT) has been consumed as a traditional remedy for Shanghuo in southern China for a long time. Shanghuo, a traditional Chinese concept, is a physiological process of uncoordinated response to stress with physical and mental fatigue syndromes. In this study, we investigated the main components and anti-stress effects of GHT in restrain-stressed mice. The high-performance liquid chromatography (HPLC) fingerprint of GHT extract was recorded and the chemicals of main peaks were identified. The effects of GHT on number and activity of nature killer (NK) and T cells, cytokines and the antioxidative activity of splenocytes were studied in restrained mice. Results showed oral administration of GHT prevented stress-induced immunocompromise by improving splenocyte number, NK cell response against mouse T cell lymphoma cells (YAC)-1 cell and antitumor T cell response against syngeneic P815 in the spleens of mice loaded with acute restraint stress. GHT also significantly improved the proportion of T-helper (Th) type lymphocyte, the production of Th cell-dependent cytokines and the antioxidative activity of splenocytes. These results indicated that GHT attenuates stress by increasing the numbers and activities of immunocytes in restraint mice, by exerting antioxidative activity directly or indirectly in immunocytes.
\end{abstract}

Key words_ _ Guangdong herbal tea, restraint stress, shanghuo, immunocompromise

\section{INTRODUCTION}

Herbal teas are consumed worldwide for their physical or medicinal effects, especially for their notable effects on stimulant, relaxant or sedative. ${ }^{1)}$ In southern China, herbal teas are usually prepared with Traditional Chinese Medicine (TCM) approach to enhance health. Guangdong Herbal Tea (GHT), well-known as Wanglaoji-Liang-Cha, has been consumed as a healthy beverage in Lingnan area of China for nearly 200 years. It is now a known herbal tea used to fight against infectious diseases, relieve fever, alleviate pain, restore strength and modulate immunity against viral epidemics. ${ }^{2)}$ GHT is made from ten kinds of Chinese herbs, which are Ilex asprella, Oroxylum indicum, Polygonum chinense, Desmadium styracifolium, Microcos paniculata, Lophatherum gracile,

*To whom correspondence should be addressed: Institute of Traditional Chinese Medicine \& Natural Products, Jinan University, 601 Huangpu Avenue West, Guangzhou 510632, China. Tel.: +86-20-85221352; Fax: +86-20-85221559; Email: hiroshi_kurihara@163.com
Lygodium japonicum, Vitex negundo, Helicteres angustifolia and Rosa laevigata. The combination of these ten herbs is used as a traditional remedy for Shanghuo. In Chinese medicine, Shanghuo is used as a general term to describe multiple syndromes, including sore throat, mouth ulcers and fever. Now it has been realized that Shanghuo is a physiological process of uncoordinated response to stress with physical immunocompromise and mental fatigue syndromes. ${ }^{3)}$ Therefore, it is necessary to apply corresponding immunity and nutrition supporting treatment to solve Shanghuo problems.

Recently, the consumption of GHT increases remarkably in Chinese communities of South Asia. However, there is little scientific research and development about GHT. Thus it is necessary to make more efforts on the studies on its components and pharmacological mechanisms. In this study, the HPLC fingerprint of GHT extract was recorded and the main peaks were identified by spectrum methods. On the other hand, we also investigated the anti-stress effects of GHT on Shanghuo in restraint-stressed mice. In previous studies, we en- 
Table 1. Crude Plants Composition of GHT

\begin{tabular}{llcr}
\hline \hline Plant name & Family & Part used & Composition \\
\hline Ilex asprella (Hook. et Arn.) Champ. ex Benth & Aquifoliaceae & Root & $308.0 \mathrm{~g}$ \\
Lophatherum gracile Brongn & Gramineae & Stem leaf & $18.0 \mathrm{~g}$ \\
Vitex negundo L. & Rutaceae & Leaf & $59.0 \mathrm{~g}$ \\
Microcos paniculata L. & Tiliaceae & Leaf & $18.0 \mathrm{~g}$ \\
Oroxylum indicum (L.) Vent. & Bignoniaceae & Seed & $1.0 \mathrm{~g}$ \\
Rosa laevigata Michx. & Rosaceae & Root & $106.0 \mathrm{~g}$ \\
Lygodium japonicum (thunb.) sw. & Lygodiaceae & Stem leaf & $104.0 \mathrm{~g}$ \\
Desmadium styracifolium $($ osb) Merr & Leguminosae & Stem leaf & $27.0 \mathrm{~g}$ \\
Polygonum chinense L. & Polygonaceae & Leaf & $46.0 \mathrm{~g}$ \\
Helicteres angustifolia L. & Firmiana & Stem & $43.0 \mathrm{~g}$ \\
\hline
\end{tabular}

sured that stress loading caused disorder of energy metabolism ${ }^{4)}$ and immunocompromise ${ }^{5)}$ by physical and mental pressure. It has been found that GHT exerted anti-fatigue effect by accelerating the utilization of sugar and fat as energy in stressed mice. ${ }^{6,7)}$ In order to make further study on the antistress activities of GHT, we investigated the effects of GHT on restraint-induced immunocompromise in this study, by evaluating the effects of GHT on nature killer (NK) cell response against YAC-1 cell, and antitumor $\mathrm{T}$ cell response against syngeneic P815 in spleens of mice loaded with acute restraint stress.

\section{MATEARIALS AND METHODS}

Materials — Mouse immunoglobulin G1fluorescein-isothiocyanate (FITC) or phycoerythrin (PE), anti-CD3 (FITC), anti-CD4 (PE), anti-CD8 (PE), and anti-NK1.1 (PE) were all purchased from Beckman (Brea, CA, U.S.A.). Sodium fluorescein (FL), 2',2'-azobis (2-amidinopropane)dihydrochloride (AAPH), and trolox (6-hydroxy2,5,7,8-tetramethylchroman-2-carboxylic acid) were purchased from Wako Pure Chemical Industries, Ltd. (Osaka, Japan). Commercial kits used for determining malondialdehyde (MDA) were purchased from the Jiancheng Institute of Biotechnology (Nanjing, China). Commercial ELISA kit for mouse interleukin (IL)-2 was purchased form Wuhan Boster Biological Technology, Ltd. (Wuhan, China). Crude herbs used for preparation of GHT were generously provided by Wanglaoji Pharmaceutical Co. Ltd. (Guangzhou, China), and authenticated by Senior Engineer Zhang (Guangzhou Institute for Drug Control, Guangzhou, China). Voucher specimens
(2006WZY0041-2006WZY00451) were maintained in Institute of Traditional Chinese Medicine \& Natural Products, Jinan University (Guangzhou, China).

Preparation of GHT — GHT used in this study was prepared according to the Standard of the Ministry of Health, with the components of formulation of GHT listed in Table 1. A mixture of 10 kinds of crude drugs was decocted with 20 parts of boiling water for $1.5 \mathrm{hr}$ to half volume. The extracted solution was centrifuged at $3500 \mathrm{rpm}$ for $30 \mathrm{~min}$, and the supernatant was filtered and then lyophilized. The chemical pattern of the extract was obtained by the HPLC analysis. In order to identify the main peaks in the HPLC profile, the extract was submitted to Dianon HP-20, Toyopearl HW40 and preparative HPLC chromatography column sequentially. From this procedure, 8 pure compounds were isolated. The structures of these compounds were identified by spectrophotometer (Waters, Milford, MA, U.S.A.), mass spectrometer (Bruker, Billerica, MA, U.S.A.), and NMR spectrometer (Bruker).

Animals and Tumor Cell Line-Male C57BL/6J mice and female DBA/2 mice, purchased from Guangdong Medical Laboratory Animals Center (Guangzhou, China) and Shanghai Slac Laboratory Animal Co. Ltd (Shanghai, China) respectively, were kept in a specific pathogen-free animal room at $(23 \pm 1)^{\circ} \mathrm{C}$ with a $12 \mathrm{hr}$ dark-light cycle and fed with standard laboratory diet and water. The animals were allowed to acclimatize to the environment for 1 week before the experiment. $\mathrm{DBA} / 2$ mice were used for weekly in vivo ascites propagation of P815 tumor cells. The care and treatment of animals were conducted in accordance with the Guide for the Care and Use of Laboratory Animals as adopted and promulgated by the United States National Institutes of Health (NIH). P815 
tumor cell line was provided by Sun Yat-sen University (Guagnzhou, China). YAC-1 tumor cell line, a Moloney virus induced mouse $\mathrm{T}$ cell lymphoma of A/SN origin, was obtained from Institute of Health Care Science (Suntory Ltd., Osaka, Japan). The YAC-1 cell was used to test the NK cytotoxic activity for its noted sensitivity to the NK cells. Cell line was cultured in Roswell Park Memorial Institute medium-1640 (RPMI-1640) containing $10 \%$ fetal bovine serum (FBS) at $37^{\circ} \mathrm{C}$ in a $5 \% \mathrm{CO}_{2}$ humidified atmosphere before tested.

Splenocytes Preparation and $T$ Lymphocyte Subsets Determination — The mice were weighed and sacrificed under anesthesia with diethyl ether. The spleens were quickly removed and weighed. Spleen index was calculated as the spleen weight $(\mathrm{mg})$ over the body weight $(\mathrm{g})$. The splenocytes were prepared by disrupting the spleen with a grinder in phosphate-buffered saline (PBS, $\mathrm{pH}$ 7.4). The total splenocyte count was determined in each sample with a blood-cell counting chamber. After a $10 \mathrm{~min}$ centrifugation $(1000 \mathrm{rpm})$ for the separation of debris, erythrocytes were lysed using ammonium chloride reagent. The cells were washed twice with PBS and suspended in $1 \mathrm{ml}$ of cold $[10 \%$ fetal calf serum (FCS)]-RPMI-1640 medium. The mononuclear cell viability was determined by trypan blue exclusion. Samples containing $1 \times 10^{6}$ mononuclear cells in $(10 \%$ FCS)-RPMI-1640 were treated with $5 \mu$ l of selected monoclonal antibodies conjugated with FITC or PE. The double-staining combinations were used as anti-CD3 (FITC)/anti-CD4 (PE), anti-CD3 (FITC)/anti-CD8 (PE) and anti-CD3 (FITC)/antiNK1.1 (PE). Mouse IgG1-FITC and IgG1-PE were used for control staining. After $15 \mathrm{~min}$ incubation at room temperature in the dark, the cells were washed with PBS and resuspended in $0.5 \mathrm{ml}$ of cold PBS and analyzed using a FACScan flow cytometer (Beckman). Usually, 10000 cells were scanned for each sample, and the findings were expressed as percentage of cells yielding a specific fluorescence in a gated lymphocyte region.

NK Cell Activity Assay — The effects of GHT on NK cell activities were investigated as we previously reported. ${ }^{8)}$ Mice were divided into four groups. The two experimental groups received oral administration of GHT dissolved in drinking water at a final concentration of 12.5 and $50 \mathrm{mg} / \mathrm{ml}$ respectively, while normal control group and stress model group received water only. The administration of GHT solution was $0.1 \mathrm{ml} / 10 \mathrm{~g}$ body weight for consecutive $5 \mathrm{~d}$. On the second day of administration, mice were physically restrained in a $50 \mathrm{ml}$ polypropylene centrifuge tube with holes for $12 \mathrm{hr}$, and then placed in the home cage with food and water before the assay. After $3 \mathrm{~d}$ of recovery, all mice were sacrificed and spleens were removed. The NK cell activities in spleen cells were determined by two fluorescent stains as Piriou reported. ${ }^{9)}$ Target cells for detection of NK cell cytotoxicity were YAC-1 cell line stained with DiO. Mixtures of the stained YAC-1 cells and the spleen cells were incubated at different ratios for $4 \mathrm{hr}$. Then the mixtures was added with propidium iodide (PI) at a concentration of $5 \mu \mathrm{g} / \mathrm{ml}$ and incubated for $15 \mathrm{~min}$ at room temperature. Flow cytometry was performed with a FACS Epics XL (Beckman) equipped with an argon laser operating at $488 \mathrm{~nm}$. Assays for each effector/target cell ratio were performed in triplicate. Results were plotted, and the number of cells required to produce $10 \%$ specific cytotoxicity (one lytic unit, 1 LU10) was established from the best fit of the curve. The number of LU10 per spleen (LU10/spleen) was thus calculated and used to express final results.

Cytotoxic T Lymphocyte (CTL) Activity Assay — The effects of GHT on CTL cell activities were investigated by intraperitoneal injection of P815 tumor cells. Mice were divided into five groups. The two experimental groups received oral administration of GHT dissolved in drinking water at a final concentration of 12.5 and $50 \mathrm{mg} / \mathrm{ml} \mathrm{respec-}$ tively, while normal control group, sensitized control group and stress model group received water only. On the second day of administration, except the normal control group, C57B1/6 mice were sensitized with an intraperitoneal injection of $1 \times 10^{7}$ P815 tumor cells as previously described. ${ }^{10)}$ Then the stress model group and the two experimental groups were physically restrained for $6 \mathrm{hr}$ for consecutive $6 \mathrm{~d}$. After $10 \mathrm{~d}$ of sensitization of P815, all mice were sacrificed and spleens were removed. Target cells for the detection of CTL cytotoxicity were P815 cell line stained with DiO. Mixtures of the stained P815 cells and the spleen cells were incubated at different ratios for $4 \mathrm{hr}$. Then the mixtures was added with PI at a concentration of $5 \mu \mathrm{g} / \mathrm{ml}$ and incubated for $15 \mathrm{~min}$ at room temperature. Flow cytometry was used to determine NK cell activity.

Cytokine Levels in the Cultured Supernatants of Splenocytes — The effects of restraint on cytokine levels in the cultured supernatants of spleno- 


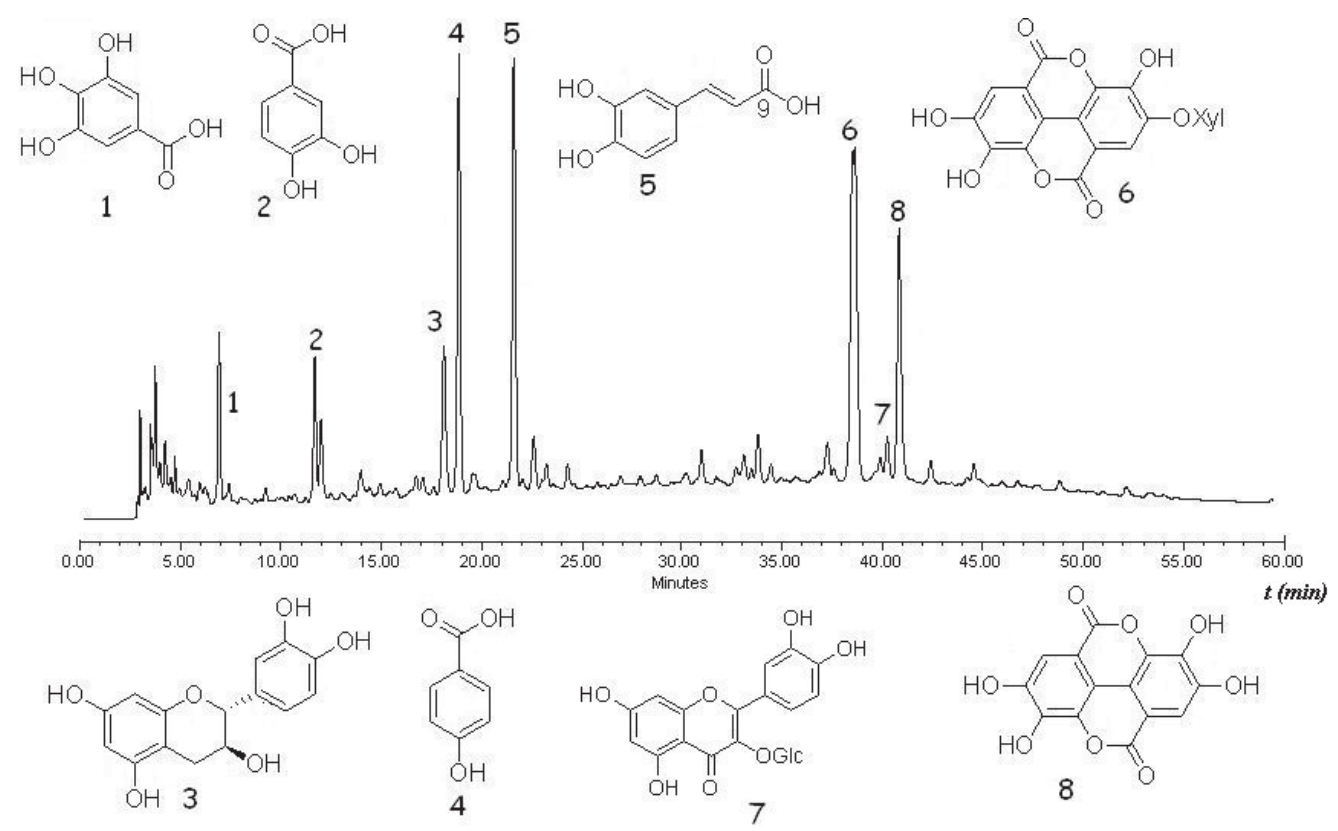

Fig. 1. Chemical Fingerprint of GHT Analyzed by HPLC

Several batches of GHT were analyzed, and similar profiles were observed. HPLC condition was as follows: Agilent series 1100 HPLC; column, Welch material XB-C18, $4.6 \times 250 \mathrm{~mm}$, particle size $5 \mu \mathrm{m}$; mobile phase $\mathrm{A}, \mathrm{H}_{2} \mathrm{O}(0.5 \% \mathrm{HAc})$; mobile phase B MeOH $(0.5 \%$ HAc); elution program: $10 \% \mathrm{~B}$ in $5 \mathrm{~min}$, linear gradient from $10 \% \mathrm{~B}$ to $64 \% \mathrm{~B}$ in $60 \mathrm{~min}$; flow rate at $0.80 \mathrm{ml} / \mathrm{min}$; detection wavelength at $254 \mathrm{~nm}$; injection volume in $10 \mu \mathrm{l}$ and oven temperature at $35^{\circ} \mathrm{C}$.

cytes were investigated. Mice were divided into four groups. In normal control group, no treatment was given to the mice. In stress model group and the two GHT groups, mice were restrained as described above. The prepared splenocytes $\left(5 \times 10^{6}\right.$ cell $\left./ \mathrm{ml}\right)$ were cultured with concanavalin A (ConA), $(10 \mu \mathrm{g} / \mathrm{ml})$ at $37^{\circ} \mathrm{C}$ for $48 \mathrm{hr}$ on $96-$ well culture plates in a $5 \% \mathrm{CO}_{2}$ humidified atmosphere. The supernatant was harvested and kept frozen at $-20^{\circ} \mathrm{C}$. Levels of IL-2 in the supernatant were determined using commercial ELISA kits.

\section{Determination of the Anti-oxidant Capability of} GHT in Vivo and in Vitro — The oxidative stress and anti-oxidative defense in lymphocytes were investigated by determining MDA content and oxygen radical absorbance capacity (ORAC) level in the prepared splenocytes. Splenocytes were homogenized in PBS at a concentration of about $2 \times 10^{7} \mathrm{cell} / \mathrm{ml}$. The MDA content in splenocytes was determined using commercial kit. The procedures for ORAC assay on spleen cells were modified from the previously described method of Kurihara. ${ }^{11)}$ The anti-oxidant capability of the GHT and its pure compounds were also studied by determining ORAC activity in vitro.

Statistical Evaluation — The data were presented as mean \pm S.D. One-way analysis of variance
(ANOVA) was applied to analyze differences in data of biochemical parameters among the experimental groups, followed by Dunnett's test for pair-wise multiple comparisons. Differences were considered as statistically significant at $p<0.05$.

\section{RESULTS}

\section{Chemical Profile of GHT Analyzed by Reverse- phase HPLC}

For the chemical identification and quality control of the preparation administrated to mice, chemical pattern of GHT was obtained by the photodiode array (PDA) HPLC analysis and indicated in Fig. 1. The GHT extract was submitted to Dianon HP-20, octadecylsilane medium-pressure liquid chromatography (ODS MPLC), Toyopearl HW40 and preparative HPLC chromatography column, yielding compounds of the main peaks. The main chromatographic peaks were identified as gallic acid $\left(1, t_{\mathrm{R}}\right.$ $6.9 \mathrm{~min})$, protocatechuic acid $\left(2, t_{\mathrm{R}} 11.7 \mathrm{~min}\right),(+)$ catechin $\left(3, t_{\mathrm{R}} 18.1 \mathrm{~min}\right)$, 4-hydroxybenzoic acid $\left(4, t_{\mathrm{R}} 18.9 \mathrm{~min}\right)$, caffeic acid $\left(5, t_{\mathrm{R}} 21.6 \mathrm{~min}\right)$, ellagic acid-4- $O$-xylopyranoside $\left(6, t_{\mathrm{R}} 38.6 \mathrm{~min}\right)$, isoquercitrin $\left(7, t_{\mathrm{R}} 40.3 \mathrm{~min}\right)$ and ellagic acid $\left(8, t_{\mathrm{R}}\right.$ $40.9 \mathrm{~min})$. 
Effects of GHT on Spleen Index and Splenocyte Number in Restraint-stressed Mice

As shown in Table 2, compared with normal control group, restraint stress reduced spleen index and total splenocyte number significantly $(p<$ 0.01). However, oral administration of GHT (125 and $500 \mathrm{mg} / \mathrm{kg}$ per day, $5 \mathrm{~d}$ ) significantly improved the spleen index and splenocyte number $(p<0.05)$.

\section{Effects of GHT on NK Cell Number and Activity in Restraint-stressed Mice}

The effects of GHT on NK cell number and activity in mice spleen were determined by flow cytometry. As shown in Table 3, the propor-

Table 2. Effects of GHT on Spleen Index and Splenocyte Number in Restraint-stressed Mice

\begin{tabular}{lcc}
\hline \hline Groups & $\begin{array}{c}\text { Spleen Index } \\
(\mathrm{mg} / \mathrm{g})\end{array}$ & $\begin{array}{c}\text { Splenocyte No. } \\
\left(\times 10^{7}\right)\end{array}$ \\
\hline Normal Control & $6.0 \pm 0.5$ & $18.8 \pm 2.6$ \\
Stress Model & $4.0 \pm 0.4^{\# \#}$ & $14.4 \pm 1.5^{\# \#}$ \\
Stress + GHT $125 \mathrm{mg} / \mathrm{kg}$ & $4.5 \pm 0.4^{*}$ & $17.6 \pm 3.0^{*}$ \\
Stress + GHT 500 mg/kg & $5.0 \pm 0.7^{* *}$ & $20.4 \pm 3.1^{* *}$ \\
\hline
\end{tabular}

Spleen index is expressed as the spleen weight (mg) over the body weight $(\mathrm{g})$. Data are expressed as mean \pm S.D. of 7 mice for each group. ${ }^{\#} p<0.01$ compared with normal control group; ${ }^{*} p<0.05$, ${ }^{* *} p<0.01$ compared with stress model group.

Table 3. Effects of GHT on NK Cell Number and Activity in Restraint-stressed Mice

\begin{tabular}{lcc}
\hline \hline Group & $\mathrm{NK}\left(\mathrm{NK}_{1.1}^{+} \mathrm{CD}^{-}\right) \%$ & $\begin{array}{c}\text { NK Cell Activity } \\
\text { (LU10/spleen })\end{array}$ \\
\hline Normal Control & $10.1 \pm 2.0$ & $20.7 \pm 2.0$ \\
Stress Model & $12.0 \pm 1.8$ & $18.1 \pm 1.50^{\#}$ \\
Stress + GHT & $12.9 \pm 1.1$ & $30.0 \pm 2.55^{* *}$ \\
$\quad 125 \mathrm{mg} / \mathrm{kg}$ & & \\
Stress + GHT & $13.8 \pm 2.1$ & $46.8 \pm 4.22^{* *}$ \\
$500 \mathrm{mg} / \mathrm{kg}$ & & \\
\hline
\end{tabular}

Data are expressed as mean \pm S.D. of 7 mice for each group. ${ }^{\#} p<$ 0.05 compared with normal control group; ${ }^{* *} p<0.01$ compared with stress model group. tions of $\mathrm{NK}\left(\mathrm{NK}_{1.1}^{+} \mathrm{CD}^{-}\right)$cell in restraint-stressed mice were not changed markedly. However, NK cell number decreased significantly in the restraintstressed mice, which may partly account for the decrease of splenocyte total number. We also investigated the effects of GHT on the activity of NK cell after the stress loading, and results showed that the activity of NK cell per spleen was suppressed by stress. However, oral administration of GHT (125 and $500 \mathrm{mg} / \mathrm{kg}$ per day, $5 \mathrm{~d}$ ) improved the suppressed activity of NK cell per spleen significantly $(p<0.01)$.

\section{Effects of GHT on the CTL Activity in Restraint- stressed Mice}

As shown in Table 4, compared with normal control group, $\mathrm{Tc}\left(\mathrm{CD}^{+} \mathrm{CD}^{+}\right)$subset of spleen lymphocyte was increased in the mouse responding to an injection of allogeneic P815 tumor cells. Compared with the sensitized control group, the percentage of $\mathrm{Th}\left(\mathrm{CD}^{+} \mathrm{CD}^{+}\right)$type of lymphocyte decreased significantly in restraint-stressed mice $(p<$ 0.01 ), but Tc type of lymphocyte was not affected significantly. The activity of CTL was also investigated in spleens of mice loaded with restrain, and results showed that CTL activity per spleen was suppressed by restrain significantly $(p<0.01)$. However, oral administration of GHT (125 and $500 \mathrm{mg} / \mathrm{kg}$ per day, $5 \mathrm{~d}$ ) improved the suppressed Th cell proportion and CTL activity per spleen significantly $(p<0.01)$.

\section{Effects of GHT on IL-2 Secretion in Restraint- stressed Mice}

Cultured mice splenocyte supernatants, stimulated with ConA, were assayed for IL-2 secretion. As shown in Fig. 2, IL-2 secretion in mice spleen was decreased after restraint stress loading. However, oral administration of GHT (125 and $500 \mathrm{mg} / \mathrm{kg}$ per day, $5 \mathrm{~d}$ ) improved the suppressed secretion of IL-2 per spleen significantly $(p<0.01)$.

Table 4. Effect of GHT on T Lymphocyte Subsets and CTL Activity in Restraint-stressed Mice

\begin{tabular}{lccc}
\hline \hline Group & Th $\left(\mathrm{CD} 4^{+} \mathrm{CD}^{+}\right) \%$ & Tc $\left(\mathrm{CD} 8^{+} \mathrm{CD} 3^{+}\right) \%$ & LU10/Spleen \\
\hline Normal Control & $18.22 \pm 1.08$ & $14.65 \pm 1.12$ & - \\
Sensitized Control & $16.13 \pm 1.86$ & $21.08 \pm 3.57^{\text {\#\# }}$ & $51.5 \pm 7.83$ \\
Stress Model & $12.8 \pm 1.08^{\mathbf{\Lambda}}$ & $19.09 \pm 3.43$ & $28.5 \pm 3.55^{\mathbf{\Lambda}}$ \\
Stress + GHT 125 mg/kg & $15.69 \pm 1.74^{* *}$ & $19.97 \pm 1.62$ & $37.9 \pm 4.49^{* *}$ \\
Stress + GHT 500 mg/kg & $15.71 \pm 2.38^{* *}$ & $20.75 \pm 2.95$ & $43.4 \pm 9.99^{* *}$ \\
\hline
\end{tabular}

Data are expressed as mean \pm S.D. of 7 mice for each group. ${ }^{\#} p<0.01$ compared with normal control group; ${ }^{\boldsymbol{\Delta} \mathbf{\Delta}} p<0.01$ compared with sensitized control group $;{ }^{* *} p<0.01$ compared with stress model group. 


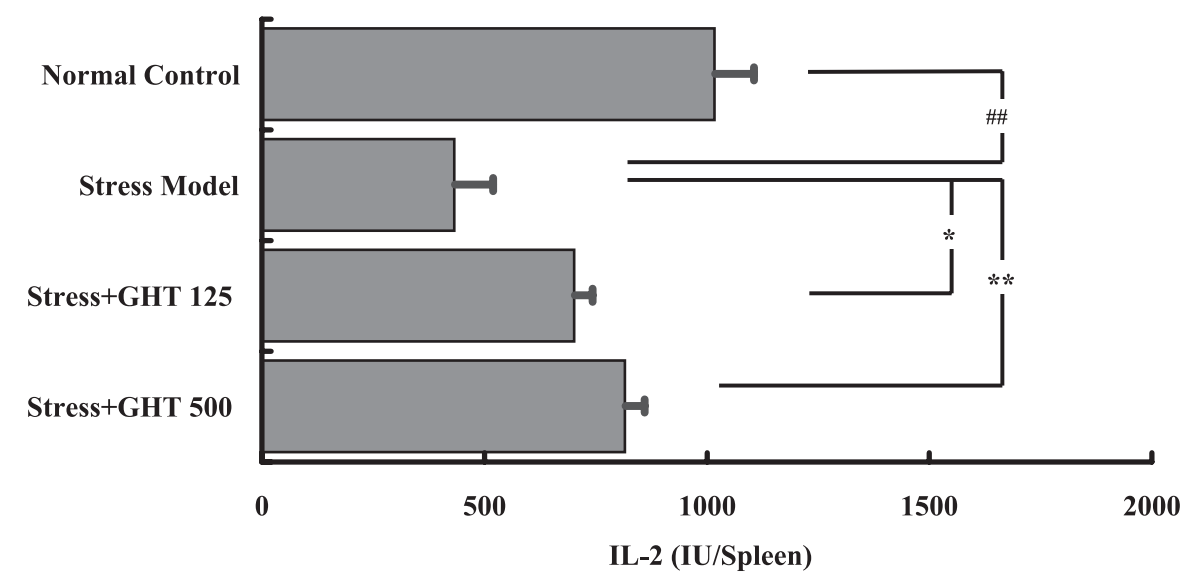

Fig. 2. Effects of GHT on IL-2 Secretion of Splenocytes in Restraint Mice

The prepared splenocytes were cultured with ConA $(10 \mu \mathrm{g} / \mathrm{ml})$ at $37^{\circ} \mathrm{C}$ for $48 \mathrm{hr}$ on 96 -well culture plates in a $5 \% \mathrm{CO}_{2}$ humidified atmosphere. The supernatant levels of IL-2 in the supernatant were determined using commercial ELISA kits. Data are expressed as mean \pm S.D. of 7 mice for each group. ${ }^{\# \#} p<0.01$, comparing with normal control group; ${ }^{*} p<0.05,{ }^{* *} p<0.01$, comparing with stress model group.

Table 5. Effects of GHT on MDA and ORAC in Splenocyte of Restraint-stressed Mice

\begin{tabular}{lcc}
\hline \hline Groups & $\begin{array}{c}\text { MDA } \\
\left(\mathrm{nM} / 2 \times 10^{7} \text { cells }\right)\end{array}$ & $\begin{array}{c}\text { ORAC } \\
\left(\mathrm{U} / 2 \times 10^{7} \text { cells }\right)\end{array}$ \\
\hline Normal Control & $2.0 \pm 0.3$ & $888.7 \pm 44.2$ \\
Stress Model & $3.6 \pm 0.3^{\# \#}$ & $661.2 \pm 37.3^{\# \#}$ \\
Stress $+\mathrm{GHT}$ & $2.6 \pm 0.5^{*}$ & $763.1 \pm 43.2^{*}$ \\
$\quad 125 \mathrm{mg} / \mathrm{kg}$ & & \\
Stress $+\mathrm{GHT}$ & $2.1 \pm 0.2^{* *}$ & $844.8 \pm 38.1^{* *}$ \\
$500 \mathrm{mg} / \mathrm{kg}$ & & \\
\hline
\end{tabular}

Data are expressed as mean \pm S.D. of 7 mice for each group. $\#$ \# $p<0.01$ compared with normal control group; ${ }^{*} p<0.05,{ }^{* *} p<$ 0.01 compared with stress model group.

\section{The Anti-oxidant Capability of GHT in Vivo and in Vitro}

As shown in Table 5, compared to normal control mice, restraint stress provoked a significant increment of MDA content $(p<0.01)$ and an obvious decrease of ORAC level $(p<0.01)$. Treatment with GHT (125 and $500 \mathrm{mg} / \mathrm{kg}$ per day) reduced MDA content $(p<0.01)$, and restored ORAC level significantly in splenocytes of restrained mice $(p<0.01)$. As shown in Fig. 3A and 3B, GHT and its isolated compounds increased the level of scavenging activity for the oxidation of fluorescein in a dose-dependent manner.

\section{DISCUSSION}

In Chinese medicine, Shanghuo is used as a general term to describe multiple syndromes, which appears inflammation symptoms as the Yin
Yang balance is disrupted by various causes. ${ }^{3)}$ Most Shanghuo-related diseases are associated with stress-induced immunocompromise. ${ }^{12)}$ In present studies, we found that restraint stress reduced spleen index and splenocyte number significantly, altered the balance of spleen lymphocyte subsets, and further suppressed NK and CTL activities. These results are identical with our previous reports, in which we demonstrated that restraint stress suppressed immunity. ${ }^{5,8)}$ GHT, which has the effect of nourishing Yin and consolidating body energy, is well accepted as treatment of Shanghuo in Lingnan area. Therefore we investigated the effects of GHT on stress-induced immune dysfunction. Results indicated that the administration of GHT to stressed mice could protect against the reduction of spleen index and spleen cells number, which initially indicated that GHT had protective effects on immunity of mice loaded with restraint stress. NK and CTL cells play an important role in immunity defense. Our results demonstrated that the proportions of NK cell in restraint-stressed mice were not changed markedly. However, as a result of decreased of total splenocyte number, the NK cell number and activity per spleen decreased markedly in restraintstressed mice. Moreover, compared with the sensitized control group, the percentage of Th type lymphocyte decreased significantly in restraint-stressed mice, but Tc type lymphocyte was not affected significantly. We also investigated the effects of restraint stress on antitumor $\mathrm{T}$ cell response against P815 cell, and results showed that restraint stress decreased the potential of the spleen cells in sensitized mice to turn into antitumor cytotoxic $\mathrm{T}$ lym- 


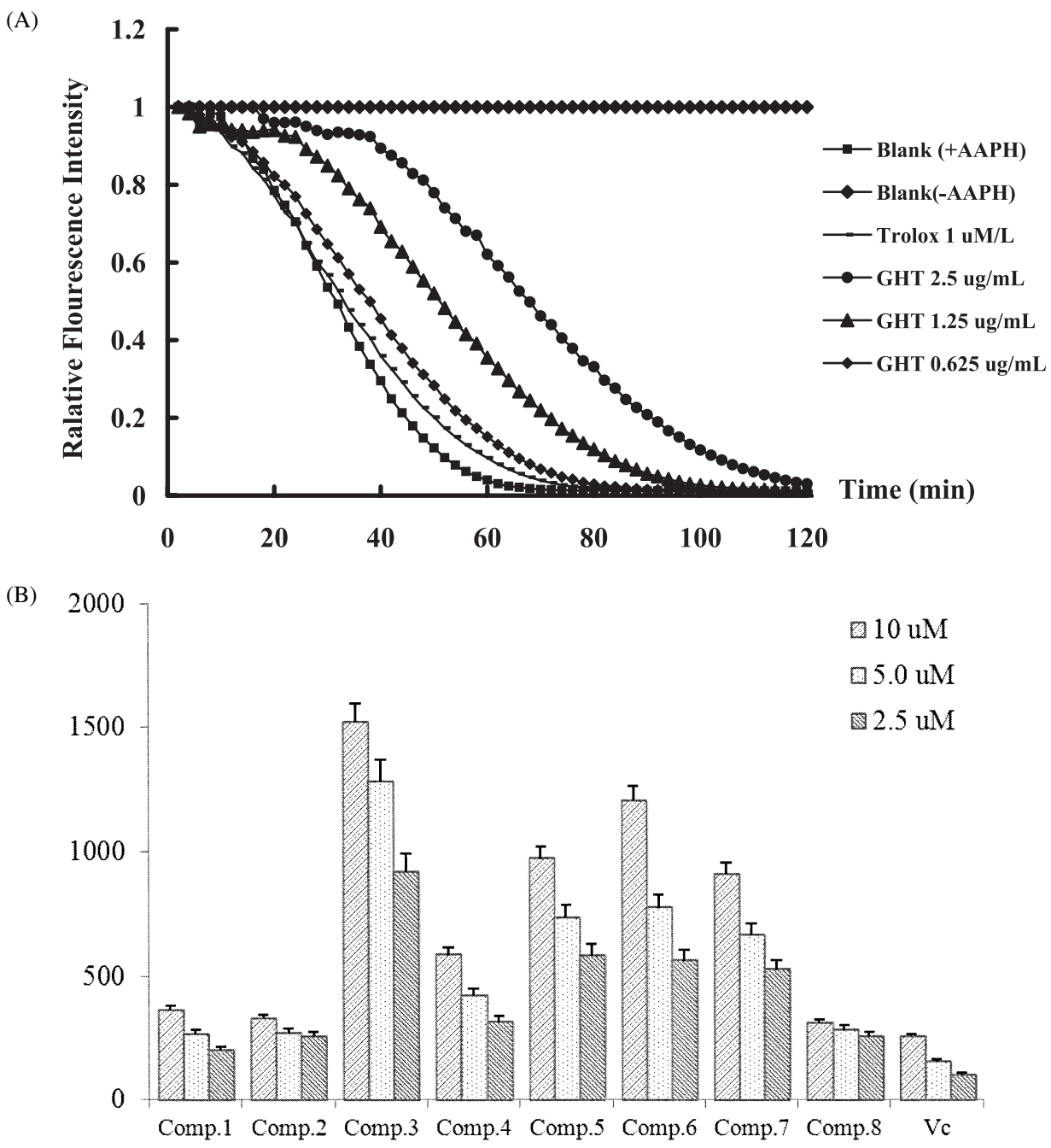

Fig. 3. Curves of Fluorescence Decay Induced by AAPH in the Presence of GHT (A) and Its Isolated Compounds (B) at Different Concentrations

Trolox, a water-soluble vitamin $\mathrm{E}$ analogue, was used as a control standard. The anti-oxidative activity of a sample was expressed as the net area under the curve. Vc was used as a positive control in Fig. 3B. One ORAC unit is calculated as $U=K\left(S_{\text {Sample }}-S_{+A A P H}\right) /\left(S_{\text {Trolox }}-S_{+A A P H}\right), K$ : samples multiple of dilution, $\mathrm{S}$ : area below the fluorescence decay curve. Data were expressed as means of three experiments.

phocytes. In the cytokine assay, stress significantly suppressed the production of tumor-specific $\mathrm{CD}^{+}$ $\mathrm{T}$ cell-dependent IL-2 in immunized spleen cells. It was reported that restraint stress-induced change in lymphocyte cell number was closely correlated with the altered antibody and cytokine levels. ${ }^{13)} \mathrm{Re}-$ ports from Sheridan's lab have shown that restraint stress suppressed T-cell cytokine production and cytolytic $\mathrm{T}$ cell activity, which could promote virusinfection in animals. ${ }^{14,15)}$ They also found that restraint stress significantly modulated NK cell trafficking and cytolytic activity and contributed to elevated virus replication. ${ }^{16)}$ In our studies, GHT protected against stress-induced immunocompromise by improving spleen NK cell activities. Oral administration of GHT also significantly improved Th type lymphocyte proportions, increased CTL activity and tumor-specific Th cell-dependent cytokine production of immunized spleen cells. These results further indicated that GHT had protective effects on immunity of mice loaded with restraint stress.

Our previous results suggested a correlation between immunologic response and antioxidative capacity in immunocytes. ${ }^{8}$ ) In this study, the oxidative and anti-oxidative situations in lymphocytes were investigated by determining MDA content and ORAC level in the prepared splenocytes. The promotion of MDA contents and the decrease of ORAC level in splenocytes suggested that restrained mice were under oxidative stress. These results indicated that stress impaired immunocompetence via oxidation. It has been reported that psychological 
stress co-occurs with oxidative injury in immune cells, which are susceptible to lose their numbers and activities due to the effects of reactive oxygen species (ROS). ${ }^{17)}$ It was reported that herbal teas was popular because of their antioxidative properties and therapeutic applications. ${ }^{18,19)}$ Recently, a comparative study showed that tropical herbal teas were more diverse in types and more variable in antioxidative values than temperate herbal teas. ${ }^{20)}$ All the ten kinds of herbs that formed GHT are originated from Lingnan area, where has a typical subtropical climate. The major constituents of GHT are polyphenols, such as gallic acid, protocatechuic acid, (+)-catechin, 4-hydroxybenzoic acid, caffeic acid, ellagic acid-4- $O$-xylopyranoside, isoquercitrin and ellagic acid, which are good antioxidants both in vitro and in vivo. ${ }^{21,22)}$ In present study, GHT compounds increased scavenging activity on the oxidation of fluorescein in a dose-dependent manner, which indicated that it was a potent antioxidant. Our results showed that the treatment with GHT could reduce MDA content and restore ORAC level in splenocytes of restrained mice. Therefore, we concluded that GHT attenuates stress by increasing the numbers and activities of splenocytes in restraintstressed mice, which may be due to its antioxidative activity directly or indirectly in immune cells.

Acknowledgements This work was supported by the Fund of National Science and Technology Development (No: 2006BAIO6A20-09) and Administration of Traditional Chinese Medicine of Guangdong Province (2010123), China.

\section{REFERENCES}

1) Gyllenhaal, C., Merritt, S. L., Peterson, S. D., Block, K. I. and Gochenour, T. (2000) Efficacy and safety of herbal stimulants and sedatives in sleep disorders. Sleep Med. Rev., 4, 229-251.

2) $\mathrm{Hu}, \mathrm{S} .-\mathrm{Y}$. (1997) Herbal teas and populace health care in tropical China. Am. J. Chin. Med., 25, 103134.

3) He, R.-R. and Kurihara, H. (2008) Shanghuo Syndrome in Traditional Chinese Medicine. Modernization of Traditional Chinese Medicine and Material Medica-World Science and Technology, 10, 37-42.

4) Kurihara, H., Yao, X.-S., Nagai, H., Tsuruoka, N., Shibata, H., Kiso, Y. and Fukami, H. (2006) The protective effect of BRAND'S Essence of Chicken (BEC) on energy metabolic disorder in mice loaded with restraint stress. J. Health Sci., 52, 17-23.

5) Kurihara, H., Koda, H., Asami, S., Kiso, Y. and Tanaka, T. (2002) Contribution of the antioxidative property of astaxanthin to its protective effect on the promotion of cancer metastasis in mice treated with restraint stress. Life Sci., 70, 2509-2520.

6) He, R.-R., Kurihara, H., Bao, L., Li, M.-M. and Yao, X.-S. (2008) Effect of Wanglaoji Cool Tea on plasma gluco metabolism and peroxidative state in stress mice. Chin. Trad. Patent Med., 30, 38-40.

7) He, R.-R., Kurihara, H., Bao, L. and Yao, X.-S. (2008) The Effect of Wang Laoji Liangcha on plasma lipids metabolism in restraint mice. China Journal of Experimental Traditional Medical Formulae, 14, 31-33.

8) He, R.-R., Yao, X.-S., Li, H.-Y., Dai, Y., Duan, Y.-H., Li, Y.-F. and Kurihara, H. (2009) The anti-stress effects of Sarcandra glabra extract on restraint-evoked immunocompromise. Biol. Pharm. Bull., 32, 247-252.

9) Piriou, L., Chilmonczyk, S., Genetet, N. and Albina, E (2000) Design of a flow cytometric assay for the determination of natural killer and cytotoxic T-lymphocyte activity in human and in different animal species. Cytometry, 41, 289-297.

10) Oughton, J. A. and Kerkvliet, N. I. (1999) Novel phenotype associated with in vivo activated CTL precursors. Clin. Immunol., 90, 323-333.

11) Kurihara, H., Fukami, H., Asami, S., Toyoda, Y., Nakai, M., Shibata, H. and Yao, X.-S. (2004) Effects of oolong tea on plasma antioxidative capacity in mice loaded with restraint stress assessed using the oxygen radical absorbance capacity (ORAC) assay. Biol. Pharm. Bull., 27, 1093-1098.

12) He, R.-R., Yao, X. and Kurihara, H. (2009) The "Xiehuo" effect of Guangdong Herbal Tea and its composition mode. Traditional Chinese Medicine and Material Medica-World Science and Technology, 11, 834-839.

13) Li, T., Harada, M., Tamada, K., Abe, K. and Nomoto, K. (1997) Repeated restraint stress impairs the antitumor $\mathrm{T}$ cell response through its suppressive effect on Th1-type CD4+ T cells. Anticancer Res., 17, 4259-4268.

14) Bonneau, R. H., Sheridan, J. F., Feng, N. and Glaser, R. (1991) Stress-induced effects on cell-mediated innate and adaptive memory components of the murine immune response to herpes simplex virus infection. Brain Behav. Immun., 5, 274-295.

15) Bonneau, R. H., Sheridan, J. F., Feng, N. and Glaser, R. (1991) Stress-induced suppression of herpes simplex virus (HSV)-specific cytotoxic T lymphocyte and natural killer cell activity and enhancement of 
acute pathogenesis following local HSV infection. Brain Behav. Immun., 5, 170-192.

16) Hunzeker, J., Padgett, D. A., Sheridan, P. A., Dhabhar, F. S. and Sheridan, J. F. (2004) Modulation of natural killer cell activity by restraint stress during an influenza A/PR8 infection in mice. Brain Behav. Immun., 18, 526-535.

17) Nakamura, K. and Matsunaga, K. (1998) Susceptibility of natural killer (NK) cells to reactive oxygen species (ROS) and their restoration by the minics of superoxide dismutase (SOD). Cancer Biother. Radiopharm., 13, 275-290.

18) Aoshima, H., Hirata, S. and Ayabe, S. (2007) Antioxidative and anti-hydrogen peroxide activities of various herbal teas. Food Chem., 103, 617-622.

19) Naithani, V., Nair, S. and Kakkar, P. (2006) Decline in antioxidant capacity of Indian herbal teas during storage and its relation to phenolic content. Food
Res. Int., 39, 176-181.

20) Chan, E. W. C., Lim, Y. Y., Chong, K. L., Tan, J. B. L. and Wong, S. K. (2010) Antioxidant properties of tropical and temperate herbal teas. Journal of Food Composition and Analysis, 23, 185-189.

21) Kumagai, J., Kawaura, T., Miyazaki, T., Prost, M., Prost, E., Watanabe, M. and Quetin-Leclercq, J. (2003) Test for antioxidant ability by scavenging long-lived mutagenic radicals in mammalian cells and by blood test with intentional radicals: an application of gallic acid. Radiation Physics and Chemistry, 66, 17-25.

22) Silva, C. G., Raulino, R. J., Cerqueira, D. M., Mannarino, S. C., Pereira, M. D., Panek, A. D., Silva, J. F. M., Menezes, F. S. and Eleutherio, E. C. A. (2009) In vitro and in vivo determination of antioxidant activity and mode of action of isoquercitrin and Hyptis fasciculata. Phytomedicine, 16, 76-77. 